\title{
The improvement effects of edible bird's nest on proliferation and activation of B lymphocyte and its antagonistic effects on immunosuppression induced by cyclophosphamide
}

\author{
This article was published in the following Dove Press journal: \\ Drug Design, Development and Therapy \\ 21 January 2016 \\ Number of times this article has been viewed
}

\author{
Ran Zhaol,* \\ Geng Li ${ }^{1} *$ \\ Xiu-juan Kong' \\ Xiu-yan Huang ${ }^{2}$ \\ Wei $\mathrm{Li}^{\prime}$ \\ Yao-ying Zeng ${ }^{2}$ \\ Xiao-ping $\mathrm{Lai}^{3}$ \\ 'Traditional Chinese Medicinal \\ College, Guangzhou University of \\ Chinese Medicine, ${ }^{2}$ Life Science \\ College, Jinan University, Guangzhou, \\ ${ }^{3}$ Dongguan Mathematical Engineering \\ Academy of Chinese Medicine, \\ Guangzhou University of Chinese \\ Medicine, Dongguan, People's Republic \\ of China
}

*These authors contributed equally to this work

\begin{abstract}
Edible bird's nest (EBN) is regarded as an immune-enhancing food in the People's Republic of China. The aim of this study is to demonstrate the efficiency of EBN in improving the immunity of mouse both in vivo and in vitro. We observed the effects of EBN on spleen lymphocytes proliferation and activation, as well as immunoglobulin isotypes as indicators. In addition, we evaluated the content of total $\operatorname{sigA}$ in the intestinal juice to assess mucosal immunity. The results showed that EBN could promote the proliferation and activation of B-cells and increase IgE, IgA, IgM, and IgG3 levels. We also found that EBN extract can promote the secretion of SIgA in the small intestine. Using cyclophosphamide (CY), we established an immunosuppressed mouse model in which we identified a reversal influence on the ratio of $\mathrm{CD}^{+} / \mathrm{CD} 19^{+}$cells, which indicates that $\mathrm{EBN}$ also protects B-cells from the damage induced by CY. We also applied polymyxin B to exclude the interference of lipopolysaccharide throughout the experiment. In conclusion, we found that EBN can reduce the intestinal immune injury induced by CY by accelerating the proliferation and activation of B-cells and enhancing antibody secretion of B-cells.
\end{abstract}

Keywords: chemotherapy, immunological enhancement, intestinal mucosal immune, EBN

\section{Introduction}

Cancer is the leading cause of death in developed countries and the second leading cause of death in developing countries. ${ }^{1}$ Chemotherapy is one of the most common therapeutic modalities and is also the only systemic therapy for the treatment of cancer. In patients with middle-stage or advance-stage cancer who cannot undergo surgery or radiotherapy, chemotherapy is the only effective method. However, chemotherapy is a double-edged sword as it not only kills cancer cells but also causes serious damage to the mucous membrane and even results in apoptosis. Numerous side effects, including mucosal dysfunction and immune impairment, seriously reduce the quality of life of patients and even may prevent further treatment in severe cases. ${ }^{2}$ Therefore, identification of a safe adjuvant medicine and reduction of immune impairment and/or any other side effects induced by chemotherapy could result in great improvement of quality of life of patients with cancer. This is also an important topic that has gained much attention and is discussed by cancer experts and scholars worldwide.

Edible bird's nest (EBN; the nest of swiftlets, known as Yanwo in Chinese), which is well known as the "Caviar of the East" due to its nutritional and pharmaceutical value, comes from swiftlets and belongs to the family Apodidae and the genera Aerodramus 
and Collocalia. ${ }^{3,4}$ Although EBN contains amino acids, carbohydrates, and mineral salts, its major ingredients are glycoproteins. ${ }^{5}$ EBN, with its sweet taste and neutral properties, can nourish lung yin, dissipate phlegm, and relieve cough and is believed to be the most effective medicine recorded in the Compendium of Materia Medica. This substance has been used as health tonic since the Tang (907 AD) and Sung (9601279 AD) dynasties. ${ }^{6}$ Despite a long history of using EBN for pharmaceutical purposes, there are few scientific reports on the medical and health benefits of EBN. The medicinal benefits of EBN have been validated based on its multiple bioactivities. Recently, scholars have found new benefits of EBN, such as potentiation of the mitogenic response of human peripheral blood monocytes and stimulation of DNA synthesis in 3 T3 fibroblasts. ${ }^{7}$ In addition, epidermal growth factor (EGF) activity has been detected by a radio-ligand receptor assay. ${ }^{8}$ EBN can enhance immune function, specifically humoral immunity and cellular immunity, via a stimulatory effect. ${ }^{9,10}$ According to certain researchers, EBN extract (EBNE) can strongly inhibit infection by influenza viruses ${ }^{11}$ and can protect articular cartilage by reducing the expression levels of matrix metalloproteinase in vivo. ${ }^{12} \mathrm{EBN}$ is reported to be antioxidant rich, and scholars have found that bioactive compounds are released from the EBN matrix when digested in the gut and are then absorbed into the gut by passive-mediated transport to exert their functional effects. ${ }^{13}$ Recently, certain researchers found that EBNEs might confer a neuroprotective effect against 6-OHDA-induced degeneration of dopaminergic neurons, particularly through inhibition of apoptosis. ${ }^{14}$ However, the study of the specific effects of EBN on B lymphocytes is still very limited. In the present study, we examined the effects of EBN on B-lymphocyte proliferation, activation, and immunoglobulin production.

\section{Materials}

\section{Mice}

$\mathrm{BALB} / \mathrm{c}$ mice (female, 18-22 g, 6-8 weeks old) were purchased from the Guangdong Medical Laboratory Animal Center (production license NO. SCXK [YUE] 2008-0002). The animals were housed in a specific pathogen-free environment (temperature $=22^{\circ} \mathrm{C} \pm 2{ }^{\circ} \mathrm{C}$; humidity $=55 \% \pm 5 \%$ ) with a 12 hours light/12 hours dark cycle. All procedures and protocols in which animals were used were approved by the Institutional Animal Care and Use Committee of Jinan University.

\section{Edible bird's nest}

The EBN for this study was purchased from Khanh Hoa Salanganes Nest Co. Ltd (Nha Trang, Khanh Hoa, Vietnam) and has been identified as the saliva of the Apodidae Aerodramus fuciphagus.

\section{EBN extraction and determination of total protein content and amino acid distribution}

EBN was dried at $50^{\circ} \mathrm{C}$ for 24 hours and then ground. The ground EBN was kept in phosphate buffered saline (PBS) at $30^{\circ} \mathrm{C}$ for 24 hours. This suspension was then fully ground using a tissue grinder, and after centrifugation for 10 minutes at $3,000 \times g$, the supernatant was collected and subjected to $0.2 \mu \mathrm{m}$ filtration (EMD Millipore, Billerica, MA, USA). The protein concentration of the EBNE was determined using the BCA Protein Assay Kit (EMD Millipore), and the amino acid distribution $(\mathrm{mg} / \mathrm{g})$ in the EBNE was determined using an L-8900 automatic amino acid analyzer (Hitachi Ltd., Tokyo, Japan). Next, $200 \mu \mathrm{L}$ SDT (4\% SDS, $100 \mathrm{mM}$ DTT, and $150 \mathrm{mM}$ Tris- $\mathrm{HCl}, \mathrm{pH} 8.0$ ) was added to the EBN protein extract and was placed in a boiling water bath for 5 minutes. The suspension was centrifuged for 5 minutes at $3,000 \times g$ and then $10 \mathrm{~mL}$ of the sonicated lysate was analyzed by SDSpolyacrylamide gel electrophoresis (SDS-PAGE).

\section{In vitro splenocyte culture}

Mice were first anesthetized by aether and sacrificed by cervical dislocation. Splenocytes were obtained using the procedure mentioned earlier, with modifications. Spleens were removed and strained through a $70 \mu \mathrm{m}$ cell strainer (Becton Dickinson, Oxnard, CA, USA). The cells were then pelleted in PBS by centrifuging at $250 \times g$ for 5 minutes at $4{ }^{\circ} \mathrm{C}$ and resuspended in $2 \mathrm{~mL}$ PBS. Red blood cells were lysed by adding $5 \mathrm{~mL} 0.15 \mathrm{M}$ ammonium chloride and $10 \mathrm{mM}$ potassium carbonate. After 5 minutes, $30 \mathrm{~mL}$ DPBS was added, and the cells were pelleted, rinsed twice with PBS, and then counted using a hemocytometer.

\section{Determination of splenocyte proliferation} via CCK-8 kit

Freshly isolated splenocytes were plated at $3 \times 10^{5}$ cells/well in $250 \mu$ L RPMI-1640 (HyClone, Logan, UT, USA) containing $10 \% \mathrm{FCS}$ (HyClone). A total of $2.5 \mu \mathrm{g}$ concanavalin A (ConA)/ $\mathrm{mL}$ or $\operatorname{EBNE}(0.19 \mathrm{mg} / \mathrm{mL}, 0.38 \mathrm{mg} / \mathrm{mL}$, or $0.75 \mathrm{mg} / \mathrm{mL})$ was dissolved in media and incubated with the cells for 48 hours at $37^{\circ} \mathrm{C}$ with $5 \% \mathrm{CO}_{2}$. Following incubation, $10 \mu \mathrm{L}$ CCK-8 (DoJinDo, Kumamoto, Japan) reagent was added to each well. ${ }^{15}$ The cells were then incubated for 4 hours with the CCK-8. Finally, the absorbance was measured at a $450 \mathrm{~nm}$ wavelength using a microplate reader (Bio-Rad Laboratories Inc., Hercules, CA, USA) to assess the proliferation of the splenocytes. 


\section{Determination of splenocyte proliferation by cytometry}

In addition to the method described above, we established another method to determine the proliferation of splenocytes using cytometry. First, freshly isolated splenocytes $\left(2 \times 10^{7} / \mathrm{mL}\right)$ were labeled with carboxyfluorescein diacetate succinimidyl ester (CFSE; Thermo Fisher Scientific, Waltham, MA, USA). The cells were then plated at $2 \times 10^{7}$ cells/well in $250 \mu \mathrm{L}$ RPMI-1640 containing $10 \%$ FCS. ${ }^{16}$ Next, $10 \mu \mathrm{g}$ lipopolysaccharide (LPS) $/ \mathrm{mL}$ and $2 \mu \mathrm{g}$ ConA $/ \mathrm{mL}$ or EBNE $(0.19 \mathrm{mg} / \mathrm{mL}, 0.38 \mathrm{mg} / \mathrm{mL}$, or $0.75 \mathrm{mg} / \mathrm{mL})$ was dissolved in media and incubated with the cells for 72 hours at $37^{\circ} \mathrm{C}$ with $5 \% \mathrm{CO}_{2}$. Following incubation, the $\mathrm{B}$ lymphocytes were stained with fluorescent chromogen-conjugated monoclonal antibodies, or anti-CD3-PE or anti-CD19-PE (Becton Dickinson), for 30 minutes at $37^{\circ} \mathrm{C}$ in the dark. The cells were then pelleted, and the supernatant was decanted, after which the cells were rinsed twice in PBS and resuspended in $1.2 \mathrm{~mL}$ plastic tubes in $500 \mu \mathrm{L}$ PBS. Data were acquired using a BD FACSCalibur flow cytometer (BD, Franklin Lakes, NJ, USA) and were analyzed with FlowJo Version 7.6.5 analysis software (Tree Star, Ashland, OR, USA).

\section{Determination of B-lymphocyte activation by cytometry}

To study the activation of B lymphocytes, after cell counting, cells were plated at $3 \times 10^{6}$ cells/well in $250 \mu \mathrm{L}$ RPMI1640 containing $10 \%$ FCS. Next, $10 \mu \mathrm{g}$ LPS $/ \mathrm{mL}$ or EBNE $(0.19 \mathrm{mg} / \mathrm{mL}, 0.38 \mathrm{mg} / \mathrm{mL}$, or $0.75 \mathrm{mg} / \mathrm{mL})$ was dissolved in media and incubated with the cells at $37^{\circ} \mathrm{C}$ with $5 \% \mathrm{CO}_{2}$. After stimulation with LPS or different concentrations of EBNE for 6 hours, 24 hours, or 48 hours, activation markers on the B lymphocytes were double stained with antiCD19-PE/anti-CD69-FITC, anti-CD19-PE/anti-CD25-FITC, or anti-CD19-PE/anti-CD71-FITC (Becton Dickinson) for 30 minutes at $37^{\circ} \mathrm{C}$ in total darkness. The samples were analyzed by flow cytometry as previously described.

\section{Determination of proliferation of B lymphocytes incubated with polymyxin B by cytometry}

Polymyxin B was chosen to eliminate the interference of LPS within the EBNE. Following the determination of B-lymphocyte proliferation by cytometry (described in section "Determination of splenocyte proliferation via CCK-8 kit"), $10 \mu \mathrm{g}$ polymyxin $\mathrm{B} / \mathrm{mL}$ and $10 \mu \mathrm{g} \mathrm{LPS} / \mathrm{mL}$ or EBNE $(0.19 \mathrm{mg} / \mathrm{mL}, 0.38 \mathrm{mg} / \mathrm{mL}$, or $0.75 \mathrm{mg} / \mathrm{mL})$ were dissolved in media and incubated with cells for 72 hours at $37^{\circ} \mathrm{C}$ with $5 \%$ $\mathrm{CO}_{2}$. Following incubation, the $\mathrm{B}$ lymphocytes were stained with anti-CD19-PE (Becton Dickinson) for 30 minutes at $37^{\circ} \mathrm{C}$ in darkness. The samples were analyzed by flow cytometry as described earlier. ${ }^{17,18}$

\section{Determination of immunoglobulin isotypes via cytometric bead array kit}

Following cell counting (described in section "In vitro splenocyte culture"), cells were plated at $3 \times 10^{6}$ cells/well in $250 \mu \mathrm{L}$ RPMI-1640 containing 10\% FCS and supplemented with amino acids, dextrose, sodium pyruvate, antibiotics, antimycotic, and 2-mercaptoethanol. Then, $10 \mu \mathrm{g} \mathrm{LPS} / \mathrm{mL}$ or EBNE $(0.38 \mathrm{mg} / \mathrm{mL})$ was dissolved in media and incubated with the cells for 72 hours at $37^{\circ} \mathrm{C}$ with $5 \% \mathrm{CO}_{2}$. Following incubation, the concentrations of $\operatorname{IgE}, \operatorname{IgA}, \operatorname{IgM}, \operatorname{IgG} 3, \operatorname{IgG} 1$, $\operatorname{IgG} 2 \mathrm{a}$, and $\operatorname{IgG} 2 \mathrm{~b}$ in the supernatant were determined using a cytometric bead array (CBA) Mouse Immunoglobulin Isotyping Kit (BD Biosciences, San Jose, CA, USA). In brief, $50 \mu \mathrm{L}$ of the mixed capture beads and $50 \mu \mathrm{L}$ BAL fluid were incubated for 1 hour at room temperature. After adding $50 \mu \mathrm{L}$ of the PE detection reagent to the mixture and incubating for 2 hours at room temperature, the beads were washed with wash buffer and analyzed with a BD FACSArray Bioanalyzer (BD Biosciences). The CBA data were analyzed with FCAP Array Version 1.0.1 software (BD Biosciences). The minimal detection limit was $1 \mathrm{ng} / \mathrm{mL}$ (for $\operatorname{IgE}, \operatorname{Ig} A, \operatorname{IgM}, \operatorname{IgG} 3$, IgG1, $\mathrm{IgG} 2 \mathrm{a}$, and $\operatorname{IgG} 2 \mathrm{~b}$ ).

\section{Determination of $\lg A$ in intestinal lavage and $\mathrm{CD}^{+} / \mathrm{CD} 19^{+}$lymphocytes among Peyer's patch cells}

After 1 week of acclimation, 25 mice were stochastically divided into five groups, named the control group, the cyclophosphamide (CY)-damaged group, and the EBNEprotected groups: the low dose (EBNL, $0.42 \mathrm{~g} / \mathrm{kg}$ ), medium dose (EBNM, $0.83 \mathrm{~g} / \mathrm{kg}$ ), and high dose (EBNH, $1.66 \mathrm{~g} / \mathrm{kg}$ ). EBNE-protected groups were treated with EBNE daily for 28 days, and the control group and damaged group were given an equivalent volume of sterile water on the same schedule. On day 27, the protected groups and the damaged group were administered CY (Aladdin Reagent Shanghai Co. Ltd, Shanghai, People's Republic of China; $100 \mathrm{mg} / \mathrm{kg}$ ) intraperitoneally to achieve immunosuppression. Twenty-four hours after administration of the drug, the mice were weighted and then sacrificed by cervical dislocation. The small intestine was aseptically removed, washed, and homogenized in PBS (Thermo Fisher Scientific). The suspension was centrifuged and an extract was isolated. The concentration of $\operatorname{IgA}$ was measured using an enzyme-linked immunosorbent assay (ELISA) kit (eBioscience, San Diego, CA, USA). 
In addition to obtaining the lavage, we searched for lymphocytes in visible Peyer's patch (PPs). Visible PPs were carefully peeled off the wall of the small intestine (ten PPs were obtained from each mouse) and were placed in a pre-cooled complete RPMI-1640 medium containing 5\% fetal bovine serum (FBS), followed by gentle homogenization and filtration through a $200 \mu \mathrm{m}$ microporous filter (Becton Dickinson). The suspension was placed in a $15 \mathrm{~mL}$ tube and centrifuged at $250 \times \mathrm{g}$ for 5 minutes at room temperature. The pellet was then disrupted and resuspended in $3 \mathrm{~mL}$ complete RPMI-1640 medium containing 5\% FBS. After counting, $10^{6}$ cells were placed in a single flow cytometry tube for cell staining. Single-cell suspensions prepared earlier were incubated with $1 \mu \mathrm{g}$ anti-CD3 or anti-CD19 antibody for 30 minutes at $37^{\circ} \mathrm{C}$ in darkness. The cells were then pelleted, and the supernatant was decanted, after which the cells were rinsed twice in PBS and then resuspended in $1.2 \mathrm{~mL}$ plastic tubes containing $500 \mu \mathrm{L}$ PBS. Data were acquired on a BD FACSCalibur flow cytometer and analyzed with FlowJo Version 7.6.5 analysis software. ${ }^{19}$

\section{Results}

\section{Determination of total protein content and amino acid distribution}

The protein concentration of the EBNE determined using the BCA Protein Assay Kit was $0.75 \mathrm{mg} / \mathrm{mL}$, and the amino acid distribution $(\mathrm{mg} / \mathrm{g})$ of the EBNE is shown in Table 1. Through SDS-PAGE analysis, it was found that the size of the protein in the EBNE was $>31 \mathrm{KD}$ (Figure 1).

Table I Amino acid distribution (mg/g) of EBNE

\begin{tabular}{llll}
\hline Name & $\begin{array}{l}\text { Total amino } \\
\text { acid (T) }\end{array}$ & $\begin{array}{l}\text { Free amino } \\
\text { acid (F) }\end{array}$ & $(\mathbf{F} / \mathbf{T}) \times \mathbf{I 0 0}$ \\
\hline Aspartic acid & 41.8 & 0 & 0 \\
Threonine & 33.1 & 0.12 & 0.36 \\
Serine & 35.4 & 0.19 & 0.54 \\
Glutamic acid & 34.6 & 0.40 & 1.16 \\
Proline & 40.3 & 0 & 0 \\
Glycine & 17.6 & 0.16 & 0.91 \\
Alanine & 20.2 & 0.20 & 0.99 \\
Valine & 31.5 & 0.14 & 0.44 \\
Methionine & 2.7 & 0.13 & 4.81 \\
Isoleucine & 14.2 & 0.14 & 0.99 \\
Leucine & 32.3 & 0.17 & 0.53 \\
Tyrosine & 33.2 & 0.18 & 0.54 \\
Phenylalanine & 28.9 & 0.15 & 0.52 \\
Histidine & 14.7 & 0 & 0 \\
Lysine & 15.1 & 0 & 0 \\
\hline
\end{tabular}

Notes: EBN was dried at $50^{\circ} \mathrm{C}$ for 24 hours and then ground. The ground EBN was kept in PBS at $30^{\circ} \mathrm{C}$ for 24 hours. This suspension was then fully ground using a tissue grinder, and after centrifugation for 10 minutes at 3,000 $\mathrm{g}$, the supernatant was collected and subjected to $0.2 \mu \mathrm{m}$ filtration. The amino acid distribution (mg/g) of the EBNE was determined using an L-8900 automatic amino acid analyzer.

Abbreviations: EBNE, EBN extract; EBN, Edible bird's nest; PBS, phosphate buffered saline.

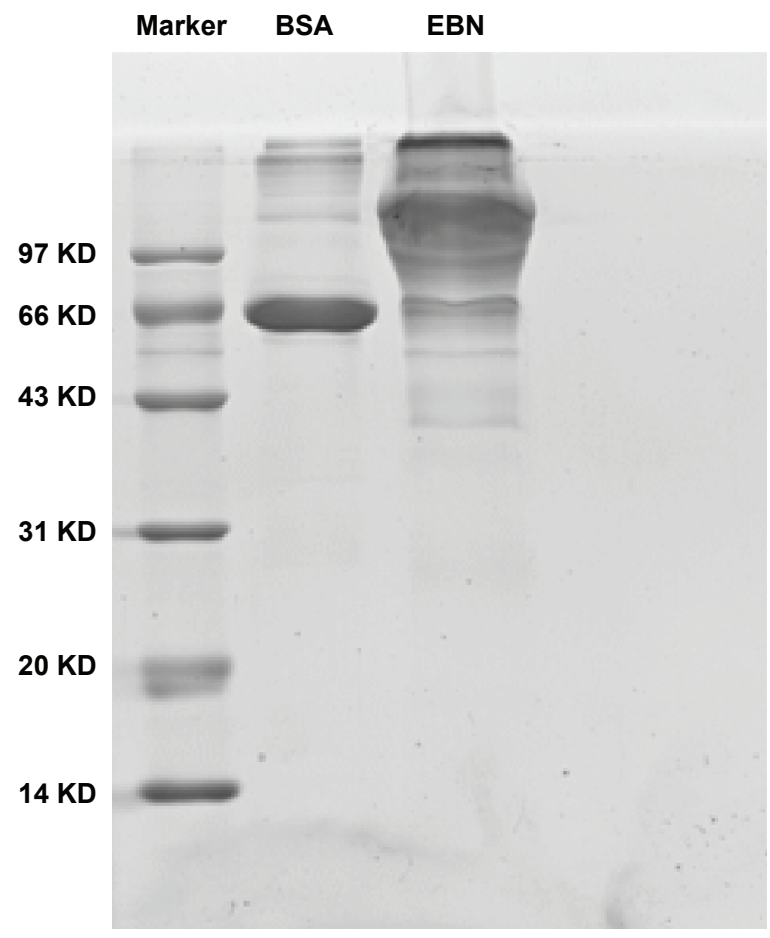

Figure I SDS-PAGE analysis of EBNE protein.

Notes: The EBN was dried for 24 hours at $50^{\circ} \mathrm{C}$ and then ground. The ground EBN was kept in PBS at $30^{\circ} \mathrm{C}$ for 24 hours. The suspension was fully ground by Tissue Grinders, and then, the supernatant was obtained after centrifugation for 10 minutes at $3,000 \times g$ and subjected to $0.2 \mu \mathrm{m}$ filtration. Protein concentration of EBN extract determined using the $B C A$ protein assay kit was $0.75 \mathrm{mg} / \mathrm{mL}$, amino acid distribution $(\mathrm{mg} / \mathrm{g})$ of EBNE was determined using L-8900 automatic amino acid analyzer. Add $200 \mu \mathrm{L}$ SDT (4\% SDS, $100 \mathrm{mM}$ DTT, $150 \mathrm{mM}$ Tris- $\mathrm{HCl}$ pH 8.0) into EBN protein extracts, then emerge into a boiling bath for 5 minutes. After centrifugation for 5 minutes, $10 \mu \mathrm{L}$ of supersonic lysate was analyzed by SDS-PAGE.

Abbreviations: SDS-PAGE, SDS-polyacrylamide gel electrophoresis; EBNE, EBN extract; BSA, bovine serum albumin; EBN, Edible bird's nest; PBS, phosphate buffered saline.

\section{EBNE stimulates splenocyte and B-cell proliferation}

We first determined the effects of EBNE on splenocyte proliferation using a CCK-8 Kit. EBNE clearly increased cell proliferation. Specifically, EBNH $(0.75 \mathrm{mg} / \mathrm{mL}$ EBNE) induced a $300.6 \%$ increase in the proliferation rate of lymphocytes compared with that in the control group (Figure 2). From the CCK-8 assay results, it was observed that EBNE greatly accelerated the growth of splenocytes.

Although we established that EBNE accelerated the growth of splenocytes, the types of lymphocytes for which the proliferation was affected were still unclear. Therefore, we sought to understand the effect of EBNE on different lymphocytes. We decided to study T-cell and B-cell proliferation; hence, $\mathrm{CD} 3$ and $\mathrm{CD} 19$ were chosen as representative markers of T-cells and B-cells, respectively.

The proliferative effects of EBNE on B-cells were further determined using flow cytometry. CFSE-labeled splenocytes were incubated with ConA or EBNE for 72 hours. 


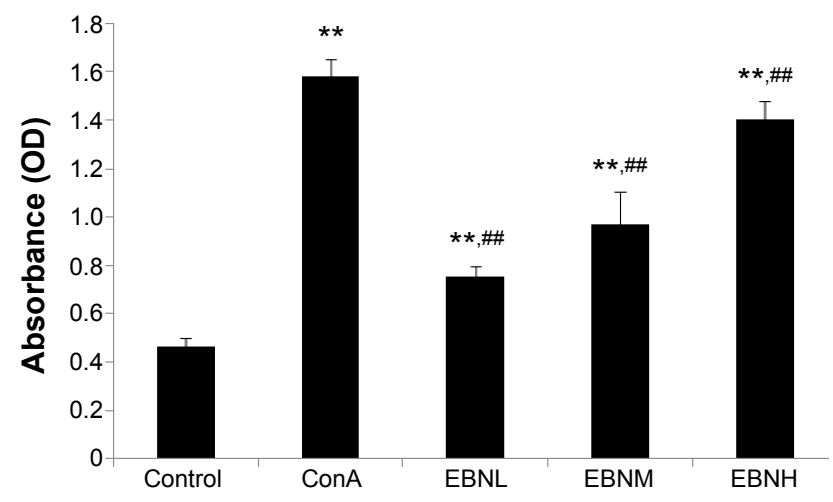

Figure 2 Effects of EBNE on the proliferation of lymphocytes.

Notes: Mouse lymphocytes were incubated at $10^{5}$ cells $/$ well for 48 hours with $2.5 \mu \mathrm{g} / \mathrm{mL}$ ConA and EBN extract at varying concentrations. Proliferation was determined by CCK-8 kit. Data are mean \pm SD ( $n=3 /$ treatment). ${ }^{* *}$ Significant difference from control group $(P<0.0 \mathrm{I})$. "\#ignificant difference from ConA group $(P<0.0 \mathrm{I})$.

Abbreviations: EBNE, EBN extract; EBN, Edible bird's nest; ConA, concanavalin $A$; SD, standard deviation; EBNL, EBN low dose; EBNM, EBN medium dose; EBNH, EBN high dose.

Subsequently, the cells were stained with anti-CD19, and cell proliferation was measured by flow cytometry. Compared with non-stimulated cells (Figure 3, PBS panel), control cells (Figure 3, LPS panel) showed six cell division cycles, with $64.03 \%$ of the cells proliferating in response to LPS. In the presence of EBNE at $0.19 \mathrm{mg} / \mathrm{mL}, 0.38 \mathrm{mg} / \mathrm{mL}$, or
$0.75 \mathrm{mg} / \mathrm{mL}, 27.59 \%, 34.13 \%$, and $40.8 \%$ of the cells, respectively, proliferated, completing six division cycles (Figure 3, EBNL, EBNM, and EBNH panels). CD19 was expressed on the B-cells, and EBNE significantly increased the proliferation rate of B-cells at all EBNE concentrations. These findings indicate that EBNE effectively accelerates the proliferation of B-cells.

After studying B-cells, we used a similar method to examine T-cells. The proliferative effects of EBNE on T-cells were specifically characterized using flow cytometry. CFSE-labeled splenocytes were incubated with ConA or EBNE for 72 hours and then stained with anti-CD3, after which cell proliferation was measured by flow cytometry. Compared with nonstimulated cells (Figure 4, PBS panel), control cells (Figure 3, ConA panel) showed four cell division cycles, with $64.03 \%$ of the cells proliferating in response to ConA. In contrast, in the presence of EBNE at $0.19 \mathrm{mg} / \mathrm{mL}$, $0.38 \mathrm{mg} / \mathrm{mL}$, or $0.75 \mathrm{mg} / \mathrm{mL}$, few cells proliferated, completing only one division cycle (Figure 4, EBNL, EBNM, and EBNH panels). CD3 was expressed on the T-cells, and EBNE barely increased the proliferation rate of T-cells at the varying EBNE concentrations. These results show that the effects of EBNE on T-cells are limited. Taken together, our

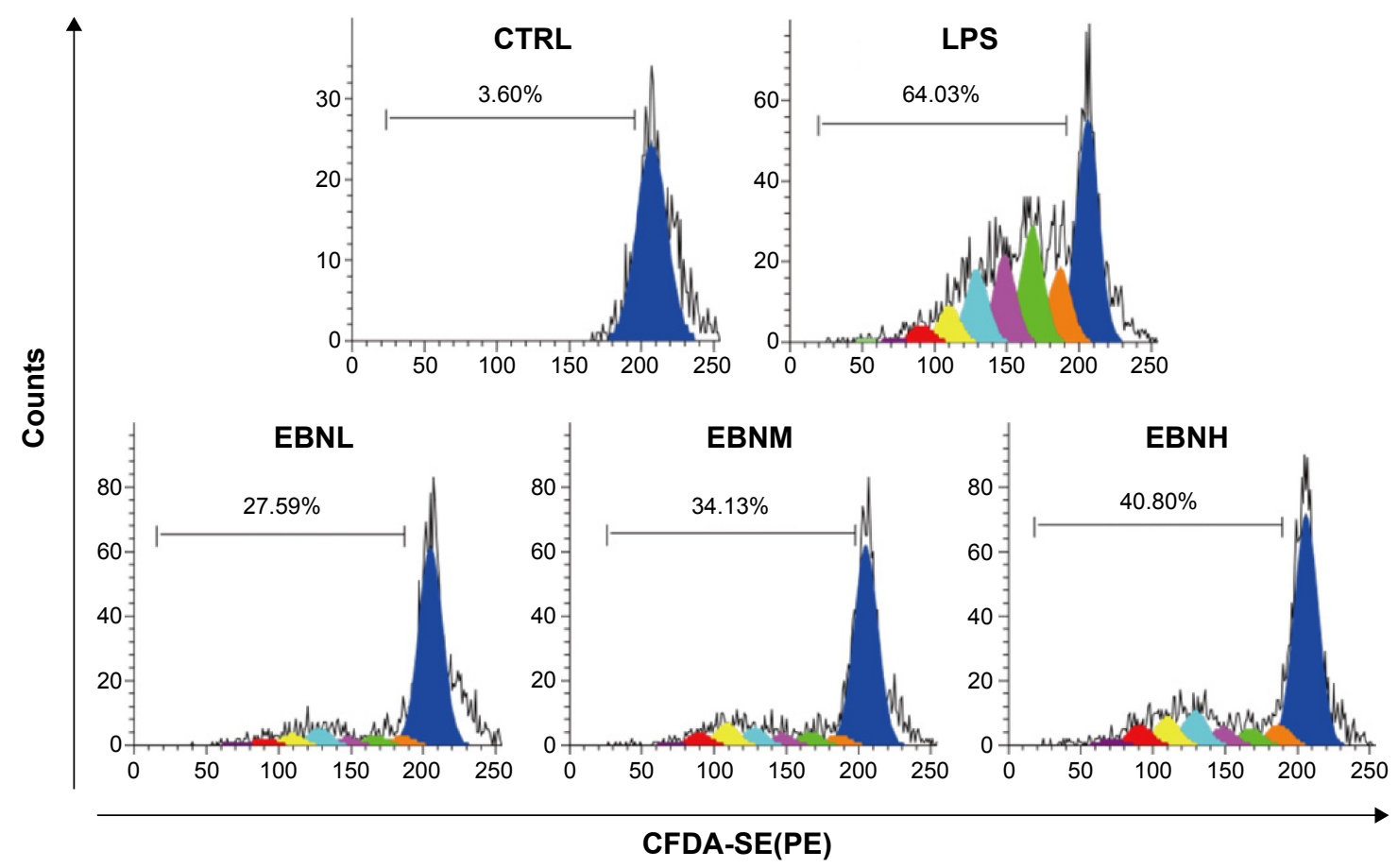

Figure 3 Effects of EBNE on the proliferation of B-cell.

Notes: CFSE-labeled splenocytes were incubated with $5 \mu \mathrm{g} / \mathrm{mL}$ LPS or EBNE at varying concentrations for 72 hours at $37^{\circ} \mathrm{C}$ with $5 \%$ CO, then stained with CDI 9 for 30 minutes at $37^{\circ} \mathrm{C}$ in darkness. The cells were washed twice with PBS, and cell proliferation was measured by flow cytometry and analyzed with Flowjo Version 7.6 .5 analysis software.

Abbreviations: EBNE, EBN extract; EBN, Edible bird's nest; CFSE, carboxyfluorescein diacetate succinimidyl ester; CTRL, control; LPS, lipopolysaccharide; EBNL, EBN low dose; EBNM, EBN medium dose; EBNH, EBN high dose; CFDA-SE(PE), carboxyfluorescein diacetate-succinimidyl ester (phycoerythrin); PBS, phosphate buffered saline. 


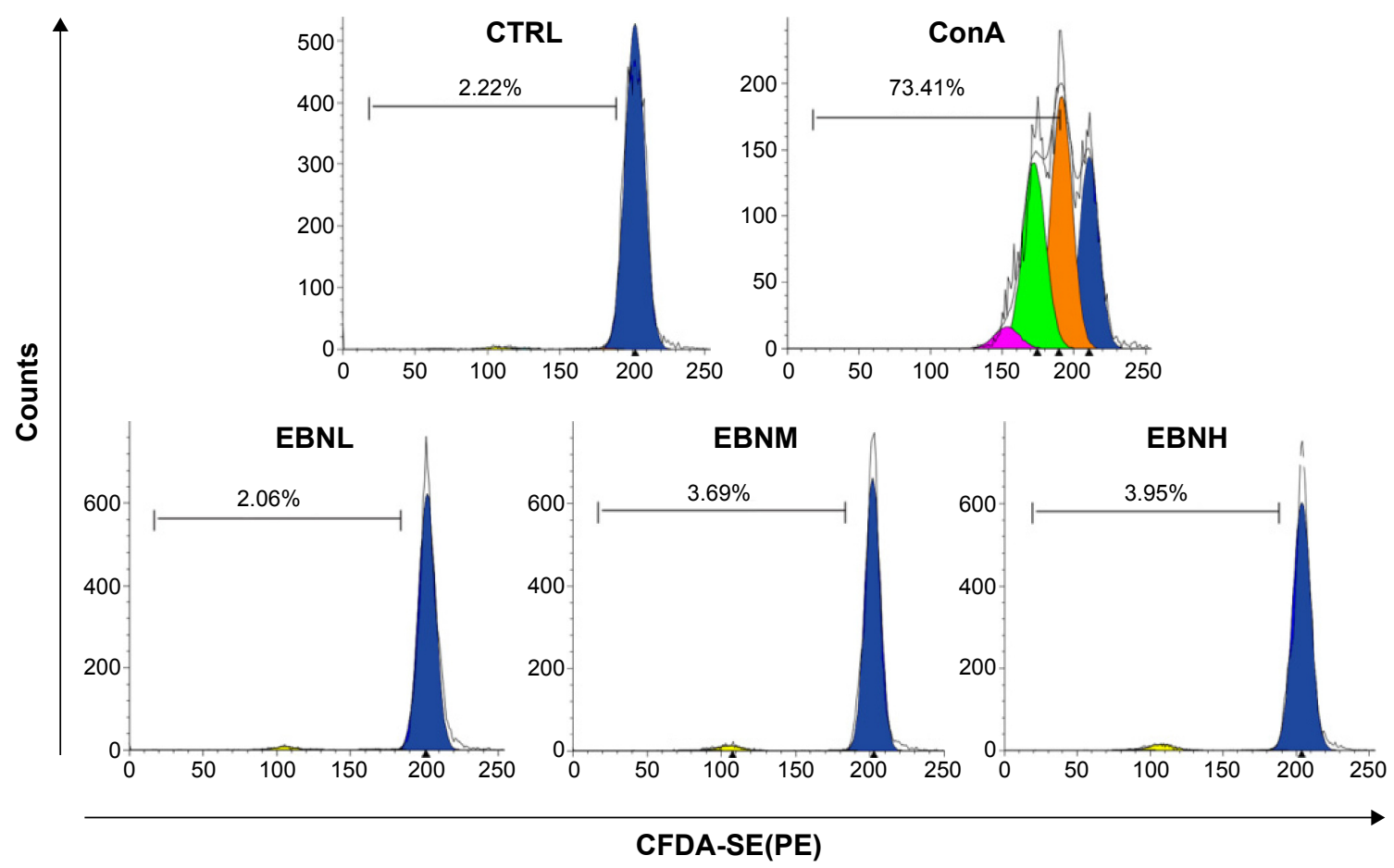

Figure 4 Effects of EBNE on the proliferation of T-cell.

Notes: CFSE-labeled splenocytes were incubated with $5 \mu \mathrm{g} / \mathrm{mL}$ ConA or EBNE at varying concentrations for 72 hours at $37^{\circ} \mathrm{C}$ with $5 \%$ CO, then stained with $\mathrm{CD} 3$ for 30 minutes at $37^{\circ} \mathrm{C}$ in darkness. The cells were washed twice with PBS, and the cell proliferation was measured by flow cytometry and analyzed with Flowjo Version 7.6 .5 analysis software.

Abbreviations: EBNE, EBN extract; EBN, Edible bird's nest; CFSE, carboxyfluorescein diacetate succinimidyl ester; ConA, concanavalin A; CTRL, control; EBNL, EBN low dose; EBNM, EBN medium dose; EBNH, EBN high dose; CFDA-SE(PE), carboxyfluorescein diacetate-succinimidyl ester (phycoerythrin); PBS, phosphate buffered saline.

findings indicate that EBNE can accelerate the proliferation of B-cells at varying EBNE concentrations $(0.19 \mathrm{mg} / \mathrm{mL}$, $0.38 \mathrm{mg} / \mathrm{mL}$, or $0.75 \mathrm{mg} / \mathrm{mL}$ ), but not T-cells.

\section{EBNE can promote B-cell activation in the early, middle, and later periods}

After identifying the enhancement of B-cell proliferation, we examined the activity of B lymphocytes, specifically, the effects of EBNE on B-cell activation. As shown in Table 2, different EBNE concentrations led to significantly increased percentages of $\mathrm{CD} 19^{+} / \mathrm{CD} 69^{+}, \mathrm{CD} 19^{+} / \mathrm{CD} 25^{+}$, and $\mathrm{CD} 19^{+} / \mathrm{CD} 71^{+}$cells compared with control treatment. Specifically, for the high dose of EBNE $(0.75 \mathrm{mg} / \mathrm{mL})$, the percentages increased to $64.4 \% \pm 1.42 \%, 46.87 \% \pm 0.93 \%$, and $72.0 \% \pm 1.92 \%$, respectively. Analysis of CD69, CD25, or CD71 expression showed that EBNE could promote the activation of B-cells in the early, middle, and later periods.

The antigens CD69, CD25, and CD71 may serve as specific markers of B-cell activation in the early, middle, and later periods. Many scholars have found that CD69 is expressed on approximately $50 \%$ of cells after 6 hours of incubation in control cultures. In the present study, after

Table 2 Effects of EBN extracts on the activation of B-cells

\begin{tabular}{|c|c|c|c|}
\hline Group & $\mathrm{CD} 9^{+} \mathrm{CD} 69^{+} / \mathrm{CD} 19^{+}(\%)$ & $\mathrm{CD}_{1} 9^{+} \mathrm{CD}^{2} 5^{+} / \mathrm{CD} 19^{+}(\%)$ & $\mathrm{CDI}^{+} \mathrm{CD}^{-} \mathrm{I}^{+} / \mathrm{CD}^{2} 9^{+}(\%)$ \\
\hline CTRL & $21.6 \pm 0.95$ & $13.37 \pm 2.65$ & $34.9 \pm 3.00$ \\
\hline LPS & $83.9 \pm 2.84 * *$ & $79.30 \pm 1.48 * *$ & $89.7 \pm 0.68 * *$ \\
\hline EBNL & $41.3 \pm 1.93 * * \ldots$ & $27.63 \pm 2.54 * * \ldots$ & $48.6 \pm 1.04 * * \ldots$ \\
\hline EBNM & $51.1 \pm 2.43 * * \ldots$ & $34.60 \pm 2.95^{* * \ldots \#}$ & $59.0 \pm 3.33^{* * \ldots \#}$ \\
\hline EBNH & $64.4 \pm 1.42 * * \ldots$ & $46.87 \pm 0.93 * * \ldots$ & $72.0 \pm 1.92 * * \ldots$ \\
\hline
\end{tabular}

Notes: Cultures were incubated with $20 \mu \mathrm{L}$ LPS $(5 \mu \mathrm{g} / \mathrm{mL})$ or different concentrations of EBNE $(0.19 \mathrm{mg} / \mathrm{mL}, 0.38 \mathrm{mg} / \mathrm{mL}$, or $0.75 \mathrm{mg} / \mathrm{mL})$ and were harvested for 6 hours, 24 hours, or 48 hours. The cells were then double stained with antibodies against CDI9 and the CD69, CD25 or CD7I antigen for 30 minutes at $37^{\circ} \mathrm{C}$ in darkness. The cells were washed and phenotyped by flow cytometry. The data are the mean \pm SD ( $\mathrm{n}=3 /$ treatment). **Significant difference from control group $(P<0.01)$. ${ }^{\prime \prime}$ Significant difference from LPS group $(P<0.01)$.

Abbreviations: EBN, Edible bird's nest; CTRL, control; LPS, lipopolysaccharide; EBNL, EBN low dose; EBNM, EBN medium dose; EBNH, EBN high dose; EBNE, EBN extract; SD, standard deviation. 
24 hours and 48 hours, CD25 and CD71 were expressed on a high percentage of cells in the non-EBNE-exposed cultures. Therefore, we used flow cytometry combined with two-color immunofluorescent staining to investigate the stimulatory effect of EBNE on B-cell activation. We measured the expression of the markers CD69, CD25, and CD71 after 6 hours, 24 hours, or 48 hours. Flow cytometry analysis showed that the effects of both LPS and EBNE treatment on the markers CD69, CD25, and CD71 were more evident than the effects of the control treatment, so we again concluded that EBNE could promote the activation of B-cells in the early, middle, and later period.

\section{Following incubation with polymyxin $B$, EBNE still promotes B-cell activation}

Polymyxin B was chosen to eliminate the interference of LPS within the EBNE; we again verified the effects of EBNE on B-lymphocyte proliferation. As shown in Table 3, the proliferation index (PI) of the LPS group administered polymyxin $B$ was significantly lower than that of the group without polymyxin B, so we concluded that polymyxin B can eliminate the interference of LPS. Furthermore, the PI of the EBNE groups with polymyxin B was similar to that of the EBNE groups without polymyxin B. Taken together, the results indicate that certain components of the EBNE, but not LPS, increased the proliferation rate of $\mathrm{B}$-cells.

All of the above-mentioned experiments demonstrated that EBNE significantly increased the proliferation rate of B-cells at varying EBNE concentrations. LPS is a major ingredient of the gram-negative bacterial cell wall and a powerful stimulant of B-cells that induces the proliferation of B-cells and also differentiates B-cells into antibody-secreting

Table 3 Determination of B-lymphocyte proliferation by cytometry-based cell counting

\begin{tabular}{lll}
\hline Group & PI (without polymyxin B) & PI (with polymyxin B) \\
\hline Control & $1.08 \pm 0.005$ & $1.08 \pm 0.005$ \\
LPS & $1.59 \pm 0.026^{\text {\&\& }}$ & $1.19 \pm 0.02^{* * . \$ \$}$ \\
EBNL & $1.12 \pm 0.011^{\text {\&\& }}$ & $1.16 \pm 0.012^{* * . \$ \$}$ \\
EBNM & $1.15 \pm 0.01^{\text {\& }}$ & $1.19 \pm 0.012^{* *, \$ \$}$ \\
EBNH & $1.14 \pm 0.005^{\text {\& }}$ & $1.24 \pm 0.02^{* * . \$ \$}$
\end{tabular}

Notes: A total of $10 \mu \mathrm{g}$ polymyxin $\mathrm{B} / \mathrm{mL}$ and $10 \mu \mathrm{g} L P S / \mathrm{mL}$ or EBNE $(0.19 \mathrm{mg} / \mathrm{mL}$, $0.38 \mathrm{mg} / \mathrm{mL}$, or $0.75 \mathrm{mg} / \mathrm{mL}$ ) were dissolved in media and incubated with cells for 72 hours at $37^{\circ} \mathrm{C}$ with $5 \% \mathrm{CO}_{2}$. Following incubation, the $\mathrm{B}$ lymphocytes were stained with anti-CDI9 for 30 minutes at $37^{\circ} \mathrm{C}$ in darkness. The samples were analyzed by flow cytometry. The data are the mean $\pm S D\left(n=3 /\right.$ treatment). ${ }^{\text {\& } ~}$ or **Significant difference from control group $(P<0.01)$. ${ }^{\$}$ The $\mathrm{PI}$ (with polymyxin $\mathrm{B}$ ) significant difference from the $\mathrm{PI}$ (without polymyxin $\mathrm{B})(P<0.0 \mathrm{I})$.

Abbreviations: LPS, lipopolysaccharide; EBNL, EBN low dose; EBNM, EBN medium dose; $\mathrm{EBNH}$, EBN high dose; $\mathrm{EBNE}$, EBN extract; PI, proliferation index; $\mathrm{SD}$, standard deviation; EBN, Edible bird's nest.
Table 4 Effect of EBN on the production of $\lg E$, $\lg A$, and $\lg M$

\begin{tabular}{llll}
\hline Group & IgE & IgA & IgM \\
\hline Control & $4.08 \pm 0.13$ & $8.74 \pm 0.71$ & $31.35 \pm 4.83$ \\
LPS & $5.43 \pm 0.1^{*}$ & $20.33 \pm 1.0 * *$ & $84.37 \pm 16.39 *$ \\
EBN & $5.28 \pm 1.1^{*}$ & $17.28 \pm 1.0 * *$ & $79.24 \pm 16.03^{*}$ \\
\hline
\end{tabular}

Notes: Cells were plated at $3 \times 10^{6}$ cells $/$ well. A total of $20 \mu \mathrm{g}$ LPS $(5 \mu \mathrm{g} / \mathrm{mL})$ or EBNE $(0.38 \mathrm{mg} / \mathrm{mL})$ was dissolved in media and incubated with the cells for 72 hours at $37^{\circ} \mathrm{C}$ with $5 \% \mathrm{CO}_{2}$. Following incubation, the concentrations of $\lg \mathrm{E}, \lg \mathrm{A}, \lg \mathrm{M}$ in the supernatant were measured using a CBA Mouse Immunoglobulin Isotyping Kit. The data are the mean $\pm S D$ ( $n=3 /$ treatment). *Significant difference from control group $(P<0.05)$. **Significant difference from control group $(P<0.0 \mathrm{I})$.

Abbreviations: LPS, lipopolysaccharide; EBN, Edible bird's nest; EBNE, EBN extract; SD, standard deviation; CBA, cytometric bead array.

cells. Because our EBNE sample included bacteria that had LPS on their surface, we suspected that LPS could have interfered with our experimental results. We eliminated LPS and thus the possible interference by adding polymyxin B. However, we still observed that the EBNE accelerated the proliferation of B-cells. Consequently, we concluded that certain components of the EBNE, other than LPS, increase the proliferation rate of B-cells. However, those components have not been determined so far, so further experiments should be performed in the future.

\section{EBNE can increase $\lg E$, $\lg A, \lg M$, and $\lg G 3$ levels}

Effects on the immunoglobulin isotypes of B lymphocytes are shown in Tables 4 and 5. To investigate the immunomodulatory effects of EBNE, antibody levels were quantified using a CBA. The LPS group exhibited an increase in the levels of immunoglobulins compared with the control group. The EBN groups had increased IgE, IgA, IgM, and IgG3 levels, but the levels of IgG1, IgG2a, and IgG2b did not significantly change compared with those in the control group.

The humoral immune system consists of B-cells and several classes of antibodies that are produced by B-cells.

Table 5 Effect of EBN on the production of $\lg G 3$, IgGI, $\lg G 2 a$, and $\operatorname{lgG} 2 \mathrm{~b}$

\begin{tabular}{lllll}
\hline Group & IgG3 & IgG I & IgG2a & IgG2b \\
\hline Control & $4.47 \pm 0.14$ & $5.37 \pm 0.7 \mid$ & $4.83 \pm 0.025$ & $4.63 \pm 0.56$ \\
LPS & $6.36 \pm 0.72 * *$ & $8.35 \pm 1.2 I^{*}$ & $9.04 \pm 2.73^{*}$ & $10.63 \pm 4.9 I^{*}$ \\
EBN & $5.85 \pm 0.63 *$ & $7.79 \pm 1.63$ & $6.87 \pm 1.14$ & $6.51 \pm 1.32$ \\
\hline
\end{tabular}

Notes: Cells were plated at $3 \times 10^{6}$ cells/well. A total of $20 \mu \mathrm{g}$ LPS $(5 \mu \mathrm{g} / \mathrm{mL})$ or EBNE $(0.38 \mathrm{mg} / \mathrm{mL})$ was dissolved in media and incubated with the cells for 72 hours at $37^{\circ} \mathrm{C}$ with $5 \% \mathrm{CO}_{2}$. Following incubation, the concentrations of $\operatorname{lgG} 3, \operatorname{lgG}$, $\lg \mathrm{g} 2 \mathrm{a}$, and $\lg \mathrm{g} 2 \mathrm{~b}$ in the supernatant were measured using a CBA Mouse Immunoglobulin Isotyping Kit. The data are the mean $\pm S D$ ( $n=3 /$ treatment). *Significant difference from control group $(P<0.05)$. **Significant difference from control group $(P<0.0 \mathrm{I})$. Abbreviations: LPS, lipopolysaccharide; EBN, Edible bird's nest; SD, standard deviation; CBA, cytometric bead array. 
In the above experiments, we found that EBNE significantly increased the activation and proliferation of B-cells at varying EBNE concentrations. We then investigated antibody production among B-cells. All types of immunoglobulins play different roles in the immune system, but more importantly, these different functions will interact with each other, combining to form stronger protection against illness. We observed that EBNE increased IgE, IgA, IgM, and IgG3 levels, so we concluded that EBNE had certain immunomodulatory effects.

\section{EBNE can promote secretion of slgA in small intestine}

Total IgA was detected by a sandwich-type ELISA. As shown in Table 6, in small intestinal lavage fluid, IgA sharply decreased after the administration of CY, reaching $63 \%$ of normal levels $(P<0.01)$. After 28 days of EBNE treatment, IgA increased. Among all effects observed, the middle-dose group showed an obvious change in IgA in the intestinal lavage.

More than $99 \%$ of immunoglobulin-secreting cells can produce sIgA after they are isolated from the entire intestine of an adult mouse; these cells are found in the proximal small intestine. One of the main roles of $\operatorname{sIgA}$ is to control the intestinal microecology, by preventing the adherence of pathogens such as bacteria, parasites, or viruses. The decrease in sIgA in the small intestine after CY treatment is the direct result of a decrease in PP B-cells. The above-mentioned experiments demonstrated that EBNE can promote the secretion of sIgA in the small intestine.

\section{EBNE has reversal influence on ratio of $\mathrm{CD}^{+} / \mathrm{CD} 19^{+}$lymphocytes}

To observe the effect of EBNE on the intestinal mucosal immune system, the counts of $\mathrm{CD}^{+} \mathrm{T}$-cells and $\mathrm{CD} 19^{+}$

Table 6 Effect of orally administered EBN on the secretion of intestinal slgA

\begin{tabular}{ll}
\hline Group & Intestinal slgA $(\mu \mathrm{g} / \mathrm{mL})$ \\
\hline Control & $13.83 \pm 0.99$ \\
Model & $8.26 \pm 1.09 * *$ \\
EBNL + model & $10.50 \pm 1.80 * * \ldots$ \\
EBNM + model & $12.87 \pm 1.38^{\#}$ \\
EBNH + model & $11.04 \pm 1.82 * * \ldots$ \\
\hline
\end{tabular}

Notes: The lumen of the proximal $10 \mathrm{~cm}$ of the small intestine was washed with $3 \mathrm{~mL}$ PBS. After centrifugation $\left(4^{\circ} \mathrm{C}, 3,000 \times \mathrm{g}\right.$ for 10 minutes $)$, the supernatant was frozen at $-80^{\circ} \mathrm{C}$ until use. Measurement of total IgA was performed using a sandwich-type ELISA. The data are the mean $\pm S D$ ( $n=6 /$ treatment). **Significant difference from control group $(P<0.01)$. ${ }^{\#}$ Significant difference from $\mathrm{CY}$ group $(P<0.0 \mathrm{I})$.

Abbreviations: EBN, Edible bird's nest; EBNL, EBN low dose; EBNM, EBN medium dose; EBNH, EBN high dose; ELISA, enzyme-linked immunosorbent assay; SD, standard deviation; PBS, phosphate buffered saline; CY, cyclophosphamide.
Table 7 Effects of EBNE on $\mathrm{CD}^{+} / \mathrm{CD} 19^{+}$lymphocytes among PP cells

\begin{tabular}{lll}
\hline Group & $\mathrm{CD}^{+}(\%)$ & CDI $^{+}(\%)$ \\
\hline Control & $29.03 \pm 1.23$ & $53.90 \pm 3.63$ \\
Model & $56.06 \pm 5.60^{* *}$ & $28.81 \pm 4.08^{* *}$ \\
EBNL + model & $44.15 \pm 5.56^{* *, \ldots \#}$ & $42.80 \pm 5.87^{* *, \ldots}$ \\
EBNM + model & $35.73 \pm 4.47^{* *, \ldots}$ & $47.41 \pm 6.39 * *, \ldots$ \\
EBNH + model & $39.59 \pm 4.96 * * \ldots \#$ & $41.31 \pm 5.66^{* *, \ldots}$ \\
\hline
\end{tabular}

Notes: After cell counting, $10^{6}$ cells were placed in flow cytometry tubes for staining of cells. Single-cell suspensions prepared as described earlier were incubated with I $\mu \mathrm{g}$ of either anti-CD3 or anti-CD 9 antibody for 30 minutes at $37^{\circ} \mathrm{C}$ in darkness. The cells were then pelleted, and the supernatant was decanted, after which the cells were washed in PBS twice and resuspended in $1.2 \mathrm{~mL}$ plastic tubes containing $500 \mu \mathrm{L}$ PBS. Data were acquired on a BD FACSCalibur flow cytometer and analyzed with Flowjo Version 7.6.5 analysis software. The data are the mean $\pm S D(n=6 /$ treatment). ${ }^{*}$ Significant difference compared with the control group $(P<0.0 \mathrm{I})$. \#ignificant difference compared with the $C Y$ group $(P<0.0 \mathrm{I})$.

Abbreviations: EBNL, EBN low dose; EBNM, EBN medium dose; EBNH, EBN high dose; PP, Peyer's patch; PBS, phosphate buffered saline; EBN, Edible bird's nest; EBNE, EBN extract; CY, cyclophosphamide.

B-cells in the PPs of CY-treated mice were measured by flow cytometry. As shown in Table 7, treatment with CY increased the percentage of $\mathrm{CD}^{+} \mathrm{T}$-cells and decreased the percentage of $\mathrm{CD} 19^{+} \mathrm{B}$-cells. However, the percentages of the $\mathrm{CD}^{+}$and $\mathrm{CD}_{19}{ }^{+}$cells were both restored in all EBNE-treated groups $(0.42 \mathrm{~g} / \mathrm{kg} / \mathrm{d}, 0.83 \mathrm{~g} / \mathrm{kg} / \mathrm{d}$, or $1.66 \mathrm{~g} / \mathrm{kg} / \mathrm{d})$, with particular significance at a dose of $0.83 \mathrm{mg} / \mathrm{kg} / \mathrm{d}$ compared with the model group. This finding indicated that EBNE might play an important role in reversing the immunosuppressive influence of CY on mice.

The antigens CD3 and CD19 are the main receptors on intraepithelial lymphocytes and lamina propria lymphocytes. The antigen CD3 is a receptor expressed on all T-cells, as it is involved in signal transduction in T-cells. The antigen CD19 is specifically expressed on the surface of B-cells and is presented on B-cells beginning from cellular differentiation into mature B-cell blasts. The level of CD19 can also be considered as an indicator of the level of B-cells. This surface antigen also helps to regulate the proliferation and activation of B-cells and is also involved in signal transduction in B-cells. In our experiments, the antigens CD3 and CD19 were used to identify T-lymphocyte subsets and B-lymphocyte subsets in mouse intestinal PP cell suspension. Under normal conditions, the lymphocyte subset ratio in intestinal mucosa-associated lymphoid tissue is maintained within a steady range. Adopting the CY-induced immunosuppressed mouse model, we found that the proportion of $\mathrm{CD} 19^{+}$cells significantly decreased, causing the proportion of $\mathrm{CD}^{+}$cells to increase. In comparison, in CY-treated mice that consumed EBN, the proportion of $\mathrm{CD}^{+}$cells decreased, and the proportion of $\mathrm{CD} 19^{+}$cells increased. The results show that EBN might 
play an important role in reversing the immunosuppressive influence of $\mathrm{CY}$ on mice.

\section{Discussion}

The major finding of this study is that EBN effectively accelerates the proliferation of B-cells and the antibody secretion of the cells. We also observed improved immunity, based on the increased levels of certain immunoglobulin isotypes. Hence, we demonstrated that EBNE can reduce the intestinal immune injury induced by $\mathrm{CY}$ by facilitating the proliferation and activation of $\mathrm{B}$ lymphocytes and by enhancing these cells' antibody-secreting function.

Cancer is one of the major diseases that pose a serious threat to the health of humankind. At present, chemotherapy is one of the most important therapies to cure cancer. However, chemotherapeutic drugs damage even the healthy cells, and several side effects may occur, leading to multiple-organ damage as well as immunosuppression. These side effects are not conducive to further tumor treatment.

We chose CY in our model because it is a common cytotoxic chemotherapeutic drug that acts as an important agent in tumor treatment and that has been the most widely used alkylating agent in chemotherapy since the late 1950s. As a chemotherapeutic drug with a high therapeutic index, $\mathrm{CY}$ has activities against a variety of cancers. However, CY also leads to myelosuppression and immunosuppression, which significantly restrict its use in clinical chemotherapy. ${ }^{20}$ In this study, to weaken the immune system, we used mice treated with CY. An immunosuppressed state was shown in the CY-treated mice compared with normal mice. Our animal experiments demonstrated that EBN not only promotes the secretion of $\operatorname{sg} \mathrm{A}$ in the small intestine but also has reversal influences on $\mathrm{CD}^{+}{ }^{+}$-cell and $\mathrm{CD} 19^{+} \mathrm{B}$-cell ratio imbalance in CY-treated mice. Our results also suggest that EBN is a promising immunomodulatory agent that may be potential for the treatment of cancer.

Another damaging aspect of $\mathrm{CY}$ as an immunosuppressive drug is that it has pleiotropic effects on both the humoral and the cellular immune systems. The results of this study show that B-cells are more sensitive to damage by CY than T-cells. The difference between these cell types is due to their different DNA repair functions or an absence of enzymes for the metabolism of CY in B-cells. In vitro experiments suggested that EBN can improve the proliferation and activation of B-cells; this finding further indicates that $\mathrm{EBN}$ has a fascinating potential application in immunosuppressing diseases.

To more deeply examine the mechanism of the effect of EBNE, we focused on immunoglobulin isotypes and antibody secretion levels. Immunoglobulins are a group of proteins that function as antibodies and are mainly distributed in the blood, the tissue fluid, and secretions. These proteins are an important indicator of the humoral immune response. Immunoglobulins can be divided into different types according to their different functional characteristics. IgG is mainly synthesized and secreted by plasma cells in the lymph nodes and spleen. IgG can be further subdivided into four subclasses: IgG1, IgG2, IgG3, and IgG4. IgG is the key antibody that mediates humoral immunity and plays a vast homeostatic role in the body. Our study suggests that EBNE can increase the production of IgG3 but has no significant effect on IgG1 or IgG2. This result suggests that EBNE can mediate the humoral immune response to a certain level. In mucosal immunity, IgA is considered as the first line of defense among all antibodies. Our results also showed that EBNE can induce a remarkable increase in IgA secretion. Taken together, both results indicate that EBNE significantly promotes SIgA secretion in the immunosuppressive mouse model induced by $\mathrm{CY}$, suggesting that EBNE has regulatory action specific to intestinal mucosal immunity. IgM has the unique ability to induce primary immune responses. Secreted IgM multimers have the largest molecular weight compared with that of other types of immunoglobulins in the body and are composed of five immunoglobulin monomers. This specialization improves antibody titers and enhances the immune effect. Hence, the results illustrate that EBN plays an important role in the early humoral immune response.

In recent decades, traditional Chinese medications used for treating myelosuppression and immunosuppression have become more and more common, and a wide range of polysaccharides extracted from natural plants have aroused much interest due to their high efficiency and low toxicity. ${ }^{21,22}$ Multiple studies have reported that polysaccharide conjunction with chemotherapy may improve quality of life, tumor response, and performance status and may reduce the toxicity of chemotherapy; the polysaccharides used include those from Sophora subprostrata and Ganoderma lucidum. Such immunostimulation might activate the body's defenses. Many published reports have indicated that polysaccharides can modulate cytokine and/or chemokine production and can stimulate the production of both pro-inflammatory and anti-inflammatory cytokines. ${ }^{23}$ The results of our experiments also indicated that $\mathrm{EBN}$ can accelerate the proliferation and activation of B-cells and can promote the secretion of antibodies. In an in vivo study, EBN relieved the immune impairment caused by CY. Taken together, all of the results suggested that EBN could serve as a promising functional 
food for wide use in conjunction with cancer chemotherapy. In addition, EBN comprises mostly glycoproteins, which suggests a new approach beyond polysaccharides.

Before the experimental stage, we first needed to learn about the construction of EBN. During the breeding season, swiftlets use saliva secreted from the sublingual glands to build nests. ${ }^{24}$ This viscous saliva is soft and sticky at first, and then it dries and hardens when exposed to air, forming what is called nest cement. ${ }^{6}$ This cement is used to bind materials such as leaves, moss, or feathers to build nests. ${ }^{25}$ The nest cement secures the bracket-shaped nest to cave walls and also forms the cup. ${ }^{26}$ In this process, leaves, moss, or feathers encourage the growth of millions of bacteria that contain LPS. We were concerned that residual LPS from the bacteria would compromise our experimental findings, so we added polymyxin B to exclude the interference of LPS. Polymyxin B is a germicide that is effective against gram-negative bacteria due to its recognition of LPS, a component of the outer membrane of gram-negative bacteria. The experimental results showed that EBNE still accelerated the proliferation of B-cells, without the interference of LPS. This finding provides strong evidence that EBN can improve the immune function.

The key ingredient of EBN is glycoproteins, and enzymolysis has been established as a technique commonly used to extract such protein in many studies. However, in the present study, we used a tissue homogenate-based method to extract water-soluble protein from EBN. Because of using this method, the content of water-dissoluble protein was high and, in fact, contained few free amino acids, and the size of the EBNE protein was more than $31 \mathrm{KD}$. This approach is a noteworthy innovation in our research. Another notable finding in this research was related to the CD3 gene, which was expressed on all T-cells and was involved in the signal transduction process, and the CD19 gene, which was found on the surface of B-cells, served as a specific regulator of B-cell activation. We classified T-cells and B-cells by quantifying the expression of CD3 and CD19. This study showed that EBN can promote the proliferation and activation of B-cells; surprisingly, there were no similar effects on T-cells. This finding showed that EBN has a selective tendency to induce proliferation and activation in lymphocytes. These notable findings aided our experimental progress, and it might help us to make use of the immunomodulatory effect of EBN in cancer chemotherapy.

\section{Conclusion}

In conclusion, this study demonstrates that EBNE significantly reduces the intestinal immune injury induced by $\mathrm{CY}$.
The underlying mechanisms are that EBN is most likely involved in the proliferation and activation of B-cells and the antibody secretion of cells. The results indicate that consuming EBN for 30 days may relieve the intestinal immune inhibition caused by chemotherapy. Therefore, we conclude and suggest that EBN might be used as an adjuvant therapy for reducing the side effects of chemotherapy.

\section{Statistics}

Statistical significance was determined by two-way analysis of variance with Bonferroni post-tests for weight curves. All other statistical significances were determined using either a nonparametric Mann-Whitney test or paired $t$-tests. Differences were considered statistically significant when $P<0.05$.

\section{Acknowledgments}

This research was supported by the Natural Science Foundation of China (Project Number: 81173498) and the Guangdong, HongKong and Macao comprehensive program for research and development of Lingnan Chinese medicine (Project Number: 2014DFH30010).

\section{Disclosure}

The authors report no conflicts of interest in this work.

\section{References}

1. Jemal A, Bray F, Center MM, Ferlay J, Ward E, Forman D. Global cancer statistics. CA Cancer J Clin. 2011;61:69-90.

2. Delaloye J, Merlani G, Petignat C, et al. Nosocomial nontyphoidal salmonellosis after antineoplastic chemotherapy; reactivation of a symptomatic colonization? Eur J Clin Microbiol Infect Dis. 2004;23(10): 751-758.

3. Kasem KK, Sheets J, Koon N. Modified electrodes with synthetic biocatalytic membranes. Biotechnol Prog. 1998;14:791-796.

4. Ma F, Liu D. Sketch of the edible bird's nest and its important bioactivities. Food Res Intern. 2012;48:559-567.

5. Kathan RH, Weeks DI. Structure studies of Collocalia mucoid. I. Carbohydrate and amino acid composition. Arch Biochem Biophys. 1969;134:572-576.

6. Koon LC, Cranbrook. Swiftlets of Borneo-Builders of edible nests in Natural History Publication (Borneo). Swiftlets of Borneo[M]. Borneo, Sabah, Malaysia. Natural History Publication. 2002:9-12.

7. $\mathrm{Ng} \mathrm{MH}$, Chan KH, Kong YC. Potentiation of mitogenic response by extracts of the swiftlet's (Collocalia) nest. Biochem Int. 1986;13: 521-531.

8. Kong YC, Keung WM, Yip TT, Ko KM, Tsao SW, Ng MH. Evidence that epidermal growth factor is present in swiftlet's (Collocalia) nest. Comp Biochem Physiol B. 1987;87:221-226.

9. Cao Y, Xu J, Wang J-F, You Y-Y, Xue C-H. Studies on immunomodulation function of Indonesia white edible bird's nest on hypoimmune mice. Acta Nutr Sin. 2012;02:168-171.

10. Hou Y, Xian X-M, Lin J-R, Lai X-P, Chen J-N. The effect of edible bird's nest (Aerodramus) on ConA-induced rats' lymphocytes transformation. China Mod Med. 2010;26:9-11.

11. Guo C-T, Takahashi T, Bukawa W, et al. Edible bird's nest extract inhibits influenza virus infection. Antiviral Res. 2006;70:140-146. 
12. Matsukawa N, Matsumoto M, Bukawa W, et al. Improvement of bone strength and dermal thickness due to dietary edible bird's nest extract in ovariectomized rats. Biosci Biotechnol Biochem. 2011;75:590-592.

13. Yida Z, Imam MU, Ismail M. In vitro bioaccessibility and antioxidant properties of edible bird's nest following simulated human gastrointestinal digestion. BMC Complement Altern Med. 2014;14:468.

14. Yew MY, Koh RY, Chye SM, Othman I, Ng KY. Edible bird's nest ameliorates oxidative stress-induced apoptosis in SH-SY5Y human neuroblastoma cells. BMC Complement Altern Med. 2014;14:391.

15. Zhang YH, Wang Y, Yusufali AH, et al. Cytotoxic genes from traditional Chinese medicine inhibit tumor growth both in vitro and in vivo. J Integr Med. 2014;12(6):483-494.

16. Purvina M, Hoste A, Rossignol JM, Lagaudrière-Gesbert C. Human hepatitis B viral e antigen and its precursor P20 inhibit T lymphocyte proliferation. Biochem Biophys Res Commun. 2012;417(4):1310-1315.

17. Blutt SE, Crawford SE, Warfield KL, et al. The VP7 outer capsid protein of rotavirus induces polyclonal B-cell activation. J Virol. 2004;78(13): 6974-6981.

18. Cavender DE, Haskard DO, Joseph B, Ziff M. Interleukin 1 increases the binding of human B and T lymphocytes to endothelial cell monolayers Br J Haematol. 2009;147(4):471-483.

19. Fan J, Xie Y, Li X, et al. The influence of Peyer's patch apoptosis on intestinal mucosal immunity in burned mice. Burns. 2009;35:687-694.
20. Ramioul H, Zutterman R. Chemotherapy with CY. Acta Clin Belg. 1961; 16:271-291.

21. Chen X, Ye Y, Cheng H, Jiang Y, Wu Y. Thermal effects on the stability and antioxidant activity of an acid polysaccharide conjugate derived from green tea. J Agric Food Chem. 2009;57:5795-5798.

22. Chen X, Lin Z, Ye Y, et al. Suppression of diabetes in non-obese diabetic (NOD) mice by oral administration of water-soluble and alkali-soluble polysaccharide. Carbohydr Polym. 2010;82:28-33.

23. Xie G, Schepetkin IA, Siemsen DW, Kirpotina LN, Wiley JA, Quinn MT. Fractionation and characterization of biologically-active polysaccharides from Artemisia tripartite. Phytochemistry. 2008;69: 1359-1371.

24. Marshall AJ, Folley F.R.S SJ. The origin of nest-cement in edible-nest swiftlets. Proc Zool Soc Lond. 1956;126:383-390.

25. Goh DLM, Chua KY, Chew FT, et al. Immunochemical characterization of edible bird's nest allergens. J Allergy Clin Immunol. 2001;107: 1082-1088.

26. Hails CJ, Kang N, Sigurdsson JB. Nest construction and egg-laying in Edible-nest Swiftlets Aerodramus spp. and the implications for harvesting. Ibis. 1991;133:170-177.
Drug Design, Development and Therapy

\section{Publish your work in this journal}

Drug Design, Development and Therapy is an international, peerreviewed open-access journal that spans the spectrum of drug design and development through to clinical applications. Clinical outcomes, patient safety, and programs for the development and effective, safe, and sustained use of medicines are a feature of the journal, which

\section{Dovepress}

has also been accepted for indexing on PubMed Central. The manuscript management system is completely online and includes a very quick and fair peer-review system, which is all easy to use. Visit http://www.dovepress.com/testimonials.php to read real quotes from published authors.

Submit your manuscript here: http://www.dovepress.com/drug-design-development-and-therapy-journal 